\title{
Coronaviruses are Zoonotic, Meaning They are Transmitted Between Animals and People.
}

\author{
Vivek Kamath* \\ Diabetic Healing Care, India
}

*Corresponding author: Diabetic Healing Care, India

\section{Opinion}

Common signs of corona virus infection include respiratory symptoms, fever, cough, shortness of breath and breathing difficulties. In more severe cases, infection can cause pneumonia, severe acute respiratory syndrome, kidney failure and even death. People who are suffering from prevailing chronic diseases such as cancer, heart disease, high blood pressure, diabetes, chronic kidney disease, etc. may die due to their weaker immunity system. Most of the people around the world died due to panic attack and due to extreme fear. A fear of not having vaccination for the virus infections has also taken a big death toll. Therefore, it is very important to build a stronger robust immune system and patients need to think positive and follow the positive approach to combat the disease.

We will discuss 3 things in these articles.

a. Understand energy concepts of the disease and healing of the same

b. How to boost our immune system either through a natural way or through energy healing system?

c. How does our subconscious mind contribute to the illness and death?

\section{Understand Energy Concepts of the Disease and Healing for the Same}

Covid 19 has a low vibration with a closed electromagnetic structure, with a resonance frequency of about $5.5 \mathrm{hz}$ to $14.5 \mathrm{hz}$. In higher frequency range it cannot be active or survive above 25.5 hz. The virus normally attacks lungs, respiratory system, kidney and liver in few cases. The way to come out of virus infection is by boosting your immune systems through food or through natural energy healing methods. Energize your immune systems to recover faster.
A body of healthy person "vibrates" in the higher ranges. However, it might drop down even if the healthy person thinks negative. It is utmost important to maintain consistency. Our body and systems are in line with earth's frequency. The earth behaves like a gigantic electric circuit. It's Electromagnetic fields surrounds and protects all living things with a natural frequency called "Schumann Resonance". (7.83 hz and it may vary too). Below steps needs to be followed for the energy healing of the respiratory systems and immune system.

How do we heal coronaviruses naturally using energy healing called "Reiki Healing" methods?

a. Heal your complete respiratory system including all organs such as nose, pharynx, larynx, trachea, bronchi and lungs regularly 3 times a day. Minimum 15 minutes of Reiki Distant healing needs to provided to all patients.

b. Heal patient's ears, eyes, sinuses (maxillary, ethmoid, sphenoid and frontal) in case of sever congestion.

c. Heal body temperature in case of high fever daily 3 times a day

d. Energize Patient's Immune system including healing thymus gland, bone marrow, White blood cells, bone marrow, spleen, complement system. Healers also needs to heal lymphatic system.

e. In case of infants, elderly aged patients, cancer patients, diabetic patients, healers needs to focus more time on healing their immune system and lymphatic system healing apart from respiratory systems.

f. If there is any issues with the kidney functioning, then healer may have to focus on healing complete excretory system 
g. Ensure patients drinks enough lukewarm water after completion of Reiki Distant healing.

h. After completion of Reiki Distant healing, patient needs to inhale hot water steam for 5 to 10 minutes. If required, they can use eucalyptus oil in hot water.

\section{How to Boost Our Immune System Naturally Through Food and Nutrients?}

Drink hot lemon water regularly. Take enough Zinc, beta carotene, Vitamin A, C, D, E and B6 in your daily diet.

Boost your immunity system by taking natural food. (vegetables, fruits, herbs and spices). For e.g. consuming garlic, ginger, turmeric, etc. in your regular diet Maintain Your blood PH Value to normal level (7.35 to 7.45). There are many research studies conducted around the world that no virus, bacteria or even cancer cells can survive when our PH value of the blood is normal or above normal level. It will thrive only PH value of the blood is acidic. Take enough sunlight in the morning or evening. This can help you to boost your immunity level especially blue rays in the sun light makes T Cells to move faster during combating process.

Ensure you get adequate sound sleep. This will help to boost your immunity level. Smiling and laughter are few natural remedies to enhance our immunity system and balance stress hormonal levels.

\section{How Does Our Subconscious Mind Contribute to the Illness and Death?}

Many people around the world are suffering from worries, fear, anger, nightmares, emotional disturbances, emotional exhaustion, stress, anxiety, used to taking chronic drugs for chronic diseases, insomnia and many psychological factors. These negative emotions lower patient's immune systems as well as brings their body, organs, cells and systems to lower vibrations. This is the time virus or bacteria can attack people. For e.g. if people are suffering from extreme fear the frequency may drop down to 0.2 to $2.2 \mathrm{hz}$. Therefore, it is very important for all of us to raise our frequencies to through conscious behaviour or through various healing methods which can bring our mind to composed state. There is a proverb that "no poison can kill a positive thinker and no medicine can save a negative thinker". Many of the people around the world died because of panic attack, fear of death, fear of not having vaccination for the disease, etc. It is how we feed our subconscious mind shapes up our recovery process from the illness. Therefore people needs to follow a positive life style, approach and remain strong by keeping our emotions and stress in control. Our subconscious mind is so powerful and $95 \%$ of the time we are using it and only $5 \%$ of the time we are using our conscious mind. When we are sleeping our subconscious mind is active. This is why it is important that we feed positive information to our subconscious mind. If we learn how to program it to take care of health or life challenges it would solve all our issues.
This work is licensed under Creative Commons Attribution 4.0 License

To Submit Your Article Click Here:

Submit Article

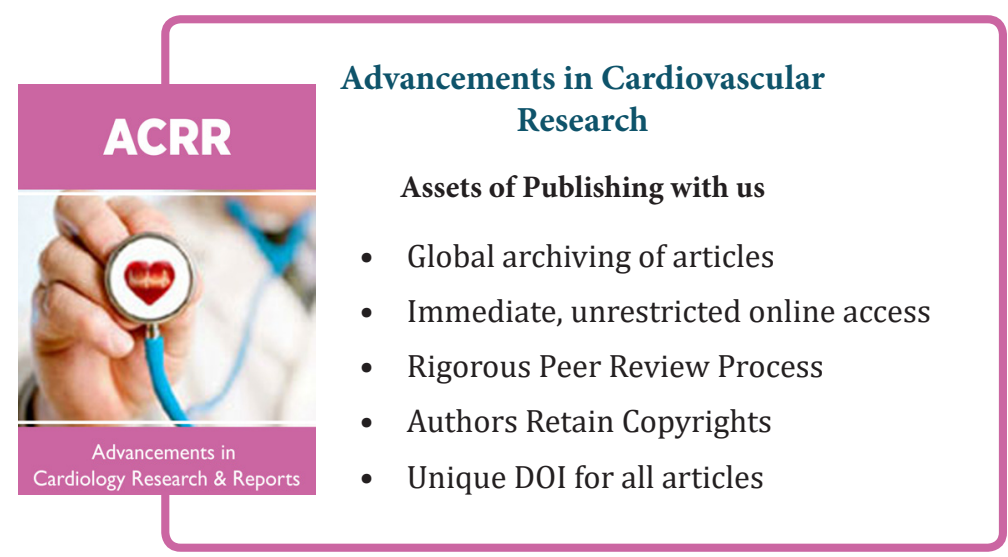

